Brazilian Journal

of Chemical

ISSN 0104-6632

Printed in Brazil

Engineering

www.scielo.br/bjce

Vol. 35, No. 03, pp. 1005-1018, July - September, 2018

dx.doi.org/10.1590/0104-6632.20180353s20170001

\title{
CHEMICAL INTERESTERIFICATION OF COTTON OIL WITH METHYL ACETATE ASSISTED BY ULTRASOUND FOR BIODIESEL PRODUCTION
}

\author{
Aldo M. Medeiros ${ }^{1, *}$, Ênio R. M. Santos ${ }^{1}$, Saulo H. G. Azevedo ${ }^{1}$, \\ Anderson A. Jesus ${ }^{1}$, Humberto N. M. Oliveira ${ }^{1}$ and Elisa M. B. D. Sousa ${ }^{1}$ \\ ${ }^{1}$ Departamento de Engenharia Química, Programa de Pós-Graduação em \\ Engenharia Química, Universidade Federal do Rio Grande do Norte, Campus \\ Universitário, Lagoa Nova, Natal, RN, CEP: 59078-970, Brazil
}

(Submitted: January 2, 2017; Revised: May 31, 2017; Accepted: June 9, 2017)

\begin{abstract}
In this study, research was performed on the interesterification reaction of cotton oil with methyl acetate, using potassium methoxide as catalyst, in the presence of ultrasonic waves. In order to obtain a better understanding of the process variables behavior, a response surface methodology was used along with statistical methods. The experiments were performed with molar ratio varying from 1:8 to $1: 24$, catalyst percentage of 0.1 to $1.3 \%$ (weight), ultrasonic nozzle amplitude varying from $30 \%$ to $90 \%$ (180 to $540 \mathrm{~W}$ ) and vibration pulse varying from $50 \%$ to $90 \%$. Process variables were optimized with the optimal molar ratio of $1: 14.87$, catalyst concentration of $1.17 \%$, ultrasonic probe amplitude of $67.64 \%$ and vibration pulse of $67.30 \%$. The average conversion of triglycerides was found to be $98.12 \%$ at the optimal conditions. The experimental data were adjusted to the second-order irreversible reaction approximation model, under optimized conditions, with temperatures of 30,40 and $50^{\circ} \mathrm{C}$. Lastly, in comparison to the conventional methodology, a significant increase of $14 \%$ of triglycerides conversion utilizing ultrasonic waves was observed.
\end{abstract}

Keywords: Esters, Gossypium hirsutum L., Sonicator, Experimental Planning, Kinetics.

\section{INTRODUCTION}

The information on renewable and clean energy production has largely increased in the last decades. The necessity of alternatives to fossil fuels resulted in extensive researches over the last years, drawing attention to the use of biodiesel, which is produced by animal or vegetable sources, and one of its greater advantages is a lower greenhouse gas emission when compared to regular diesel (Behçet et al., 2015).

The main procedures for biodiesel production are esterification and transesterification, with both being the most performed procedures by industries. The transesterification reaction consists of a reaction of a triglyceride and an alcohol, producing biodiesel, which is an ester, and glycerol as a sub-product. (Sánchez-Cantú et al., 2014). However, the amount of glycerol produced is higher than the acceptable, resulting in an unwanted sub-product, because of its low market value (Bonet et al., 2009). As an alternative to transesterification, interesterification is a new biodiesel production process, free of glycerol, which has been developed over the last few years (Casas et al., 2011a; Galia et al., 2014; Maddikeri et al., 2013). This new process consists of a reaction of triglyceride with three molecules

*Corresponding author. E-mail address: aldomiro_m@hotmail.com 
of acetate, producing three molecules of esters (biodiesel) and one molecule of triacetin. This reaction has as intermediate products monoacyldiglycerol and diacylmonoglycerol (Maddikeri et al., 2013), as shown in Figure 1. Triacetin is mainly used in pharmaceutical and cosmetics industries, and also used as a plastifier and an additive in tobacco. Recent studies have demonstrated that triacetin can be added to the formulation of biodiesel (up to $10 \%$ in weight) without impairing its performance, as it continues to satisfy the quality standards established by ASTM D6451 and EM 14214, due to its mutual solubility (Casas et al., 2010).

Biodiesel production by the acetate route is a reaction that presents as its main characteristic a shorter reaction time when compared to other processes (Casas et al., 2011a). The product purification is simpler, reaching high performance and generating a sub-product that has good market value and can be used as an additive to biodiesel. As a consequence of the high applicability of triacetin, biodiesel production by interesterification is a promising alternative to transesterification and its excessive glycerol production (Casas et al., 2010).

Interesterification has been mainly studied in the presence of enzymes (Du et al., 2004; Usai et al., 2010) or under supercritical conditions (Saka and Isayama, 2009; Tan et al., 2010, 2011). Supercritical and enzymatic methods have their advantages and disadvantages. The main disadvantages include very high pressure $(20-50 \mathrm{MPa})$ and high temperatures (350-400 ${ }^{\circ} \mathrm{C}$ ), resulting in higher heating that increases costs, as well as higher costs for the unreacted methyl acetate evaporation (Campanelli et al., 2010). The enzymatic route of interesterification generates an elevated production cost (Meher et al., 2006). Besides that, it is difficult to manufacture on larger scale, due to the necessity of a careful control of the reaction parameters and the slow reaction (Cerveró et al., 2008). Studies conducted show that the operational conditions for biodiesel production by the acetate route are close to ambient conditions; therefore, the process costs are lower than in supercritical conditions. Reaction time is relatively low, presenting a major advantage over the enzymatic catalysis (Maddikeri et al., 2013). As a consequence, it becomes interesting to study the production of biodiesel via the acetate route with chemical catalysts. Recently, some catalysts, such as methoxide, potassium hydroxide and polyethylene glycolate were studied (Casas et al., 2011a, 2011b, 2013). Casas et al. (2013) worked with sunflower oil interesterification catalyzed by methanolic potassium methoxide and found that this catalyst provided a yield of $77.0 \%$ of methyl esters and $12.1 \%$ of triacetin using a molar ratio of $1: 48$ and $0.1 \%$ of catalyst, concluding<smiles>[R]C(=O)OCC(COC([R])=O)OC([R])=O</smiles><smiles>[R3]C(=O)OCC(COC([R])=O)OC(C)=O</smiles><smiles>[R]C(=O)OCC(COC([R])=O)OC(C)=O</smiles><smiles>[R]C(=O)OCC(COC(C)=O)OC(C)=O</smiles><smiles>[R3]C(=O)OCC(COC(C)=O)OC(C)=O</smiles>

Diacetinmonoglyceride

Methyl Acetate<smiles>[R3]C(=O)OC</smiles>

Figure 1. Interesterification reaction. 
that this catalyst provides better yields among the others.

Maddikeri et al. (2013) studied biodiesel production using a sonicator (ultrasonic probe) and verified a significant increase in yield in comparison to conventional techniques. Moreover, the synthesized biodiesel properties were highly satisfactory. The excess of reagents needed was also inferior, compared to conventional techniques. According to Mostafaei et al. (2015) this increase in yield and reaction speed in the biodiesel production is directly related to the contact between the reactive molecules. The use of ultrasonic technology provides the formation of an emulsion between the oil and the acetate, resulting in high quality biodiesel in a short time span. This emulsion is caused by an event called cavitation. Subhedar and Gogate (2016) affirmed that cavitational effects can improve the mass transfer at mild reaction conditions in terms of temperature and pressure resulting in a faster reaction rate, higher product yield and possibly the requirement of lower acetate to oil molar ratio and catalyst loading. Experimental results showed that these collapsing cavities reach temperatures of up to $5000{ }^{\circ} \mathrm{C}$ and pressures of up to $1000 \mathrm{bar}$, with a life span of a few microseconds (Bang and Suslick, 2010; Suslick, 1990). An extensive study of cavitation technique is presented by Gogate and Kabadi (2009), who report that cavitation promotes the generation of hot spots, highly reactive free radicals, and turbulence associated with liquid circulation currents, which can result in the intensification of various physical/ chemical operations.

Ultrasound was used as well by Subhedar and Gogate (2016) in the production of biodiesel by enzymatic interesterification from waste cooking oil. Although the increase in yield was only $6.7 \%$ (when compared to a conventional technique), the authors say that the use of ultrasound results in a significant reduction in the reaction time with higher yields and lower requirement of enzyme loading. The results obtained have clearly established that ultrasoundassisted interesterification was a fast and efficient approach for biodiesel production, giving significant benefits, which can help in reducing the costs of production. Gole and Gogate (2013) report that transesterification using microwaves and ultrasound requires a lower amount of energy compared to the conventional approach, and also that the maximum energy requirement for ultrasound is for preheating of oil, in order to avoid the attenuation effect of ultrasound (it has been observed that about $50 \%$ of the energy is required for preheating of oil). Gole and
Gogate (2012) report that, in general, it can be said that ultrasonic reactors offer a promising future for the intensification of biodiesel production from sustainable raw materials. In addition, important parameters to be optimized include equipment operating parameters (irradiance frequency, irradiation intensity and energy dissipation per unit volume) and geometric parameters (reactor configuration and number and location of transducers).

Based on this analysis, the objective of this paper was to evaluate the behavior of cotton oil (Gossypium hirsutum $\mathrm{L}$ ) when subjected to interesterification under the effect of ultrasonic waves, analyzing the effect of the main process variables on the conversion to esters. The study includes the optimization of independent variables of the process, the determination of kinetic parameters using the second-order irreversible reaction approximation model, and a comparison between the biodiesel production assisted by ultrasound and the conventional technique.

\section{MATERIALS AND METHODS}

\section{Materials}

Refined cotton oil was obtained directly from Icofort, a Brazilian company. Methyl acetate $(99.5 \%$ purity), potassium methoxide in methanol $(25 \%$ in mass) and phosphoric acid (ORTHO) were obtained from Sigma-Aldrich, as well as the analytical standards for the esters and the triacetin (chromatography grade): methyl heptadecanoate $(99.0 \%$ purity) and F.A.M.E. $\operatorname{mix}(\mathrm{C} 8-\mathrm{C} 24)$.

\section{Experimental}

Figure 2 shows the experimental apparatus used to perform the interesterification reactions. A 150 $\mathrm{mL}$ cylindrical reactor was equipped with a reflux condenser (to avoid methyl acetate loss), thermocouple, thermostatic bath (TE-18 - Tecnal, Brazil) and an ultrasound with a probe (VCX 600 Sonics \& Materials, USA) to promote the emulsification of the solution.

The experiments were performed following the methodology used by other authors (Casas et al., 2013; Maddikeri et al., 2013), with the reactor being operated in batches, then fed with $100 \mathrm{~g}$ of reactional mixture, composed of cotton oil and methyl acetate in proportions described by Table 1 . The solution was heated up to the desired temperature $\left(50^{\circ} \mathrm{C}\right)$ and, after stabilization, the catalyst (potassium methoxide in methanol) was added to the reactor, this being the zero point of the reaction. After 30 minutes of reaction, 


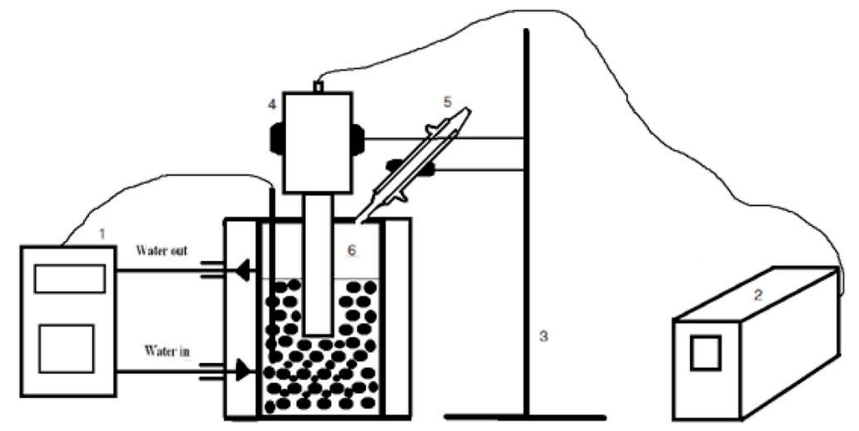

Figure 2. Experimental apparatus. 1. Temperature controller 2. Ultrasonic wave generator. 3. Shaft. 4. Ultrasonic probe. 5. Condenser. 6. Reactor.

a $10 \mathrm{~mL}$ sample of the solution was collected and an equimolar solution of phosphoric acid was immediately added to the aliquot, in order to stop the reaction.

After the phosphoric acid treatment, the sample was washed with $10 \mathrm{~mL}$ of distilled water, and then centrifuged to remove the potassium phosphate salts formed. Then, it was put in an air circulation oven (MA 035 Marconi, Brazil) at $40{ }^{\circ} \mathrm{C}$ for 24 hours to remove the methyl acetate and any remaining water. The samples were refrigerated and stored at temperatures less than $15^{\circ} \mathrm{C}$ until posterior analysis.

The use of response surface methodology along with statistical techniques can be applied to study complex processes, being used to evaluate the importance of independent variables. The statistical study is important to achieve a better comprehension of the process, reducing the amount of stock and capital investment (Oasmaa et al., 2009). Therefore, a central composite planning was used to optimize experimental conditions of the cotton oil interesterification reaction. The evaluated parameters were the molar ratio of oil/ acetate, mass percentage of catalyst in relation to the oil, ultrasound amplitude percentage and vibration pulse percentage with 1 second cycle. The variation range and their codified values are shown in Table 1.

Based on previous papers (Maddikeri et al., 2013; Mostafaei et al., 2015), the temperature was set to 50
${ }^{\circ} \mathrm{C}$, the reaction time to 30 minutes and the ultrasonic probe diameter to $28 \mathrm{~mm}$. Other variables used in the study are shown in Table 1, in which the values were set based on the studies of Maddikeri et al. (2013) and Mostafaei et al. (2015).

The software Statistic 8.0 was used to predict the model that describes the influence of each parameter on the conversion of triglycerides to esters, as well as their optimized variables. Then, experiments were performed under optimized conditions (molar ratio of $1: 14.87$; catalyst concentration of $1.17 \%$; ultrasonic probe amplitude of $67.6 \%$ and; vibration pulse of $70 \%$ ), to verify the model's consistency. In the kinetic study, aliquots of $2 \mathrm{~mL}$ were removed after $0.25,0.5$, $0.75,1,1.25,1.5,3,4,5,6,7,8,9,10,12.5,15,17.5$, 20 and 30 minutes, and the samples were treated and analyzed in a similar way to the previously mentioned. Finally, experiments with a similar methodology using a conventional approach of mechanical agitation were performed to verify the influence of the cavitation on biodiesel production.

\section{Analytical Method}

The adopted methodology was similar to that used by other authors (Jesus et al., 2013; Trentin et al., 2011; Yin et al., 2008), in which the level of esters in the reaction mixture was quantified by gas chromatography. A sample of $100 \mathrm{mg}$ was transferred to a $10 \mathrm{~mL}$ flask and the volume was completed with n-heptane. Methyl heptadecanoate was used as the internal standard of the injected solution for chromatographic analysis. The gas chromatrograph was equipped with a Shimadzu 2010 DIC flame ionization detector and a DB Waxetr Carbowax (J \& W Scientific - USA) capillary column (30 m x 0.25 $\mathrm{mm})$. The column temperature was kept at $170{ }^{\circ} \mathrm{C}$ for 1 minute, and then was raised to $230{ }^{\circ} \mathrm{C}$ at a rate of 5 ${ }^{\circ} \mathrm{C} \mathrm{min}{ }^{-1}$, maintaining this temperature for 30 minutes. The analysis was performed with the injector and the detector at $230{ }^{\circ} \mathrm{C}$.

Table 1. Real and codified values of the studied variables.

\begin{tabular}{|c|c|c|c|c|c|c|}
\hline \multirow{2}{*}{ Variables } & \multirow{2}{*}{ Label } & \multicolumn{5}{|c|}{ Codified values } \\
\hline & & $-2(-\alpha)$ & -1 & $\mathbf{0}$ & 1 & $+2(+\alpha)$ \\
\hline Molar ratio oil $/$ acetate $(\mathrm{mol} / \mathrm{mol})$ & A & $1: 8$ & $1: 12$ & $1: 16$ & $1: 20$ & $1: 24$ \\
\hline Catalyst concentration (\%) & B & 0.1 & 0.4 & 0.7 & 1.0 & 1.3 \\
\hline Ultrasonic amplitude (\%) & $\mathrm{C}$ & 30 & 45 & 60 & 75 & 90 \\
\hline Vibration pulse $(\%)$ & $\mathrm{D}$ & 50 & 60 & 70 & 80 & 90 \\
\hline
\end{tabular}


The conversion of triglycerides was calculated from the ratio of the triglyceride concentration in the sample $\left(C_{T G}\right)$ and its concentration at the beginning of the reaction $C_{T G_{0}}$, according to equation (1):

$$
\text { Conversion }(\%)=\frac{C_{T G}}{C_{T G 0}} \cdot 100 \%
$$

\section{Kinetic parameters - Second-order irreversible reaction approximation}

The literature presents two approaches related to the kinetic study of the interaction reaction with methyl acetate: the first model, which considers only the kinetics of triglyceride conversion, indicating a second-order reaction and requiring a minimum amount of catalyst to initiate the reaction; the second theoretical model, obtained by considering the main and secondary reactions, adjusted the experimental results well (Casas et al., 2011a). In this paper, the kinetic parameters (rate constant and activation energy) were evaluated considering the second-order irreversible reaction approximation (first model). In other words, the global interesterification was considered to follow the reaction according to the methodology used in the literature (Casas et al., 2011a; Maddikeri et al., 2013; Narváez et al., 2007).

The data obtained for the conversion with time were analyzed for the determination of the kinetic rate constant. The considered irreversibility of this reaction was favored by the excess of methyl acetate, which induces low concentrations of triglycerides in the equilibrium composition, similar to an irreversible reaction. (Maddikeri et al., 2013).

Equation (2) represents the model of second-order irreversible reaction approximation, in which it is assumed that triglycerides (TG) react irreversibly to the products and require only a minimal amount of catalyst to initiate the reaction. Thus, if this model is valid, a graph of $1 / \mathrm{C}_{\mathrm{TG}}$ versus $\mathrm{t}$ will be a straight line, and the slope value will be the rate constant.

$$
\begin{aligned}
& -\frac{d C_{T G}}{d t}=r_{T G}=k^{\prime} \cdot C_{T G}^{2} \\
& k^{\prime}=k \cdot C_{A C}
\end{aligned}
$$

where $\mathrm{C}_{\mathrm{TG}}$ is the molar concentration $\left(\mathrm{mol} \mathrm{L}^{-1}\right)$ of the triglycerides, $\mathrm{C}_{\mathrm{AC}}$ is the molar concentration (mol L-1) of acetate, $\mathrm{t}$ is the reaction time (minutes), $\mathrm{k}^{\prime}$ is the reaction rate constant $\left(\mathrm{L} \mathrm{mol}^{-1} \mathrm{~min}^{-1}\right)$ and $\mathrm{r} \mathrm{TG}$ is the reaction rate of the triglycerides.
In order to determine the reaction activation energy $\left(E_{a}\right)$ the Arrhenius equation was used, as shown in equation (3):

$$
k^{\prime}=k_{0} \cdot \exp \left[\frac{-E_{a}}{R T}\right]
$$

where $\mathrm{T}$ represents the temperature $(\mathrm{K}), \mathrm{R}$ is the universal gas constant $\left(\mathrm{J} \mathrm{mol}^{-1} \mathrm{~K}^{-1}\right)$ and $\mathrm{k}_{0}$ is the preexponential frequency factor.

\section{RESULTS AND DISCUSSION}

\section{Ultrasound experiments - statistical analysis}

Table 2 presents the results obtained regarding the conversion of esters in the different experimental conditions implemented. Through the experimental planning used, the variables that had the most significant statistical effects on the response variables were evaluated, either in the linear part or in the quadratic part. The results showed that the catalyst concentration (linear part) was the most significant variable, followed by the molar ratio (quadratic part), catalyst concentration (quadratic part), molar ratio (linear part), amplitude (quadratic part) and pulse (linear part). The other variables did not have significant statistical effects at the $95 \%$ confidence interval, but their effects were considered in the statistical model to obtain a better description of the process.

A quadratic regression model was developed, using values coded from the estimated data. The equation for the model developed is represented by equation (4).

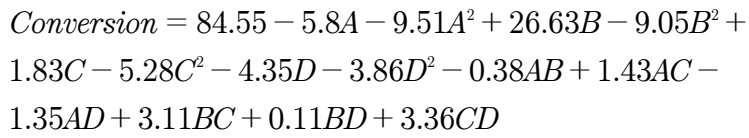

In this model, all linear and quadratic factors were introduced, as well as the interactions between two terms. Table 3 shows the analysis of variance for the quadratic model developed by the software. The model was adjusted for a confidence limit of $95 \%$ and a coefficient of determination $\left(\mathrm{R}^{2}\right)$ of 0.964 was found, suggesting that the model can explain $96.4 \%$ of the observed values. The ratio between the F-value and $\mathrm{F}_{\mathrm{x}, \mathrm{y}}$ equal to 10.39 and 0.19 referring to the residuals and the lack of adjustment, respectively, imply that the model can be considered as significant and predictive, for there is no sign of lack of adjustment. 
Table 2. Experimental planning matrix with results.

\begin{tabular}{|c|c|c|c|c|c|}
\hline Experiment & $\mathrm{A}$ & B & $\mathrm{C}$ & $\mathrm{D}$ & Conversion $(\%)$ \\
\hline 1 & $1: 16$ & 0.7 & 90 & 70 & 66.63 \\
\hline 2 & $1: 12$ & 1.0 & 45 & 60 & 94.64 \\
\hline 3 & $1: 20$ & 1.0 & 75 & 80 & 88.57 \\
\hline 4 & $1: 20$ & 0.4 & 75 & 60 & 24.40 \\
\hline 5 & $1: 12$ & 0.4 & 45 & 60 & 38.91 \\
\hline 6 & $1: 16$ & 0.1 & 60 & 70 & 4.37 \\
\hline 7 & $1: 12$ & 1.0 & 75 & 80 & 92.00 \\
\hline 8 & $1: 20$ & 1.0 & 75 & 60 & 93.49 \\
\hline 9 & $1: 16$ & 0.7 & 60 & 50 & 74.44 \\
\hline 10 & $1: 20$ & 0.4 & 45 & 60 & 34.32 \\
\hline 11 & $1: 20$ & 1.0 & 45 & 80 & 58.34 \\
\hline 12 & $1: 16$ & 0.7 & 60 & 90 & 63.66 \\
\hline 13 & $1: 16$ & 0.7 & 60 & 70 & 93.57 \\
\hline 14 & $1: 12$ & 1.0 & 75 & 60 & 89.44 \\
\hline 15 & $1: 16$ & 1.3 & 60 & 70 & 92.24 \\
\hline 16 & $1: 8$ & 0.7 & 60 & 70 & 66.33 \\
\hline 17 & $1: 20$ & 1.0 & 45 & 60 & 86.02 \\
\hline 18 & $1: 20$ & 0.4 & 75 & 80 & 19.12 \\
\hline 19 & $1: 12$ & 0.4 & 75 & 60 & 35.18 \\
\hline 20 & $1: 16$ & 0.7 & 30 & 70 & 60.15 \\
\hline 21 & $1: 20$ & 0.4 & 45 & 80 & 20.01 \\
\hline 22 & $1: 16$ & 0.7 & 60 & 70 & 85.15 \\
\hline 23 & $1: 12$ & 0.4 & 45 & 80 & 23.14 \\
\hline 24 & $1: 16$ & 0.7 & 60 & 70 & 79.56 \\
\hline 25 & $1: 12$ & 0.4 & 75 & 80 & 28.30 \\
\hline 26 & $1: 24$ & 0.7 & 60 & 70 & 26.60 \\
\hline
\end{tabular}

\section{Effects of the Process Variables}

In order to analyze the $3 \mathrm{D}$ response surface effect of the process variables for the production of cotton oil biodiesel by interesterification, in the presence of ultrasonic waves, variables for the optimal condition were set. The variables of interest, in the current study, were used according to the experimental interval. The response surface of the process variables effects is presented in Figure 3(a-d).

\section{Effects of the Catalyst Concentration}

The potassium methoxide concentration in methanol was investigated in the interesterification reaction in the interval of 0.1 to $1.3 \%$, in relation to the mass of oil. The highest conversion of triglycerides was obtained at the catalyst concentration of $1 \%$, where $94.64 \%$ conversion was achieved. In terms of percentage variation, the catalyst concentration $(0.1$ a $1.3 \%)$, caused a percentage variation in the conversion (in percentage terms), between 1.42 and $95.3 \%$, depending on the other experimental conditions adopted (molar ratio, ultrasonic vibration pulse and amplitude). The results are presented in Figure 3(b, d). It has been verified that the increase in the catalyst concentration from 0.1 to $1.17 \%$ increased the reaction conversion, because low concentrations of potassium methoxide result in the incomplete conversion of the triglycerides into methyl esters, corresponding to the biodiesel (Maddikeri et al., 2013).

In contrast, an additional increase beyond $1.17 \%$ in the catalyst concentration did not cause a significant increase in the conversion of biodiesel. Maddikeri et al. (2013) pointed out similar tendencies in the interesterification reaction of used cooking oil, where the increase in catalyst concentration from 1 to $1.25 \%$ did not cause an increase in the reaction performance. Casas et al. (2011a) worked on the interesterification reaction of refined sunflower oil with potassium methoxide and optimized their catalyst percentage at $0.1 \%$, in relation to the weight of the oil. As observed, a small amount of catalyst can result in low percentages in the reaction conversion. However, high concentrations can cause resistance to mass transfer, slowing down the reaction rate, therefore decreasing the percentage conversion of biodiesel (El-Gendy et al., 2015). Other authors reported that, in biodiesel production by transesterification, an excess of catalyst originates the formation of emulsion, that leads to the formation of gels, which cause a decrease in the ester percentage in the final mixture (Suppalakpanya et al., 2010).

\section{Effects of the Ultrasound Amplitude}

The percentage of the ultrasonic probe amplitude determines the amount of energy that will be provided to the system, deciding the extension of the

Table 3. Analysis of variance (ANOVA) in the quadratic model.

\begin{tabular}{lccccc}
\hline Source & Sum of Squares & Degree of Freedom & Mean Square & F-value & Prob $>$ F \\
\hline Regression & 23935.79 & 14 & 1709.70 & 26.48 & 10.39 \\
Residual & 839.20 & 13 & 64.55 & 71.11 & 0.19 \\
Lack of fit & 711.05 & 10 & 42.72 & \\
Pure error & 128.15 & 3 & & \\
Total & 24774.99 & 27 & & \\
\hline
\end{tabular}



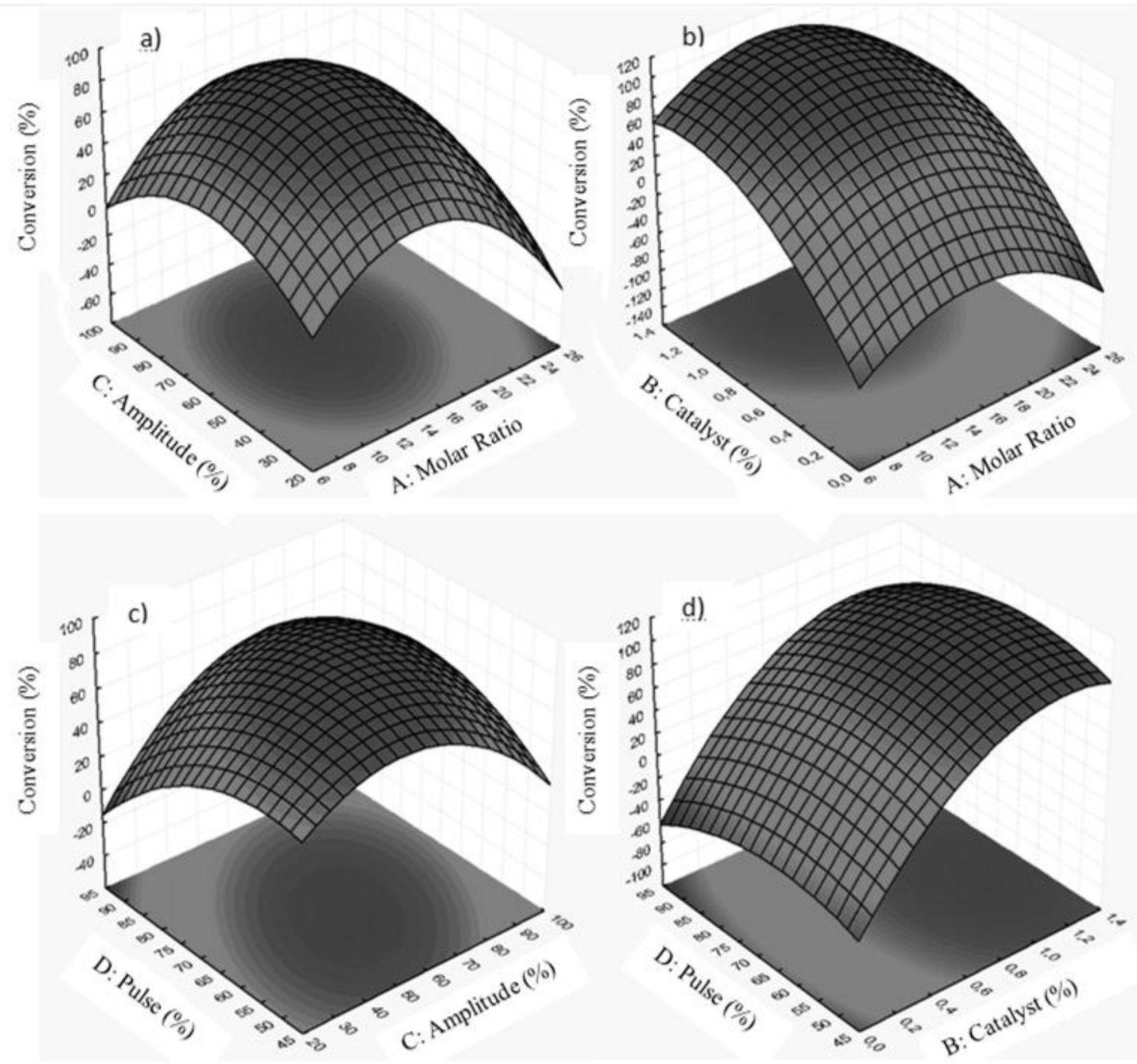

Figure 3. 3D response surface that represents the process variables effects over the process of biodiesel production.

cavitation activity in the reactor, influencing the final conversion of the biodiesel production in the reaction of interesterification. The effect of the percentage of the amplitude of the ultrasonic probe varied from 30 to $90 \%$, corresponding to the interval of 180 to 540 $\mathrm{W}$, respectively. In terms of percentage variation, the ultrasound amplitude (30 to $90 \%$ ) caused a variation in the conversion (in percentage terms) between 4.44 and $35.7 \%$, depending on the other experimental conditions adopted (molar ratio, pulse and catalyst concentration). The response surface results are presented in Figure 3(a, c), where an increase in the reaction conversion can be observed with the increase of the amplitude up to a percentage of $67.64 \%$ (405.84 W). An additional increase beyond this percentage did not provide any relevant increase in conversion.
The increase in the reaction conversion with the increase in the amplitude of the ultrasound may be attributed to the cavitation effects. A higher level of these effects ensures an emulsification between layers of the mixture, that is to say, results in greater contact between the reagent molecules. For additional amplitude percentages beyond the optimal percentage, cavitation effects may result in a cushioning of the cavity collapse, resulting in a decrease in the energy transfer throughout the system, giving less cavitation activity and, consequently, lower reaction conversion (Maddikeri et al., 2013). Maddikeri et al. (2013) reported tendencies similar to the ones obtained in the present study. They used percentage amplitudes of the ultrasonic probe of 40, 50, 60 and 70\%, corresponding to $300,375,450$ and $525 \mathrm{~W}$, respectively, and found the optimal condition at $450 \mathrm{~W}$. 


\section{Effects of the Ultrasonic Vibration Pulse}

The ultrasonic vibration pulse determines the emission time of the ultrasonic waves in a given cycle. In the experiments, cycles of 1 second and pulse percentages of $50,60,70,80$ and $90 \%$ were used, that is, when the experiment used a pulse of $60 \%$ the ultrasound would emit waves for 0.6 seconds and rest for 0.4 seconds. The vibration pulse is an important factor, because it creates the possibility to save energy in the process. In terms of percentage variation, an ultrasonic vibration pulse (50 to $90 \%$ ) caused a variation in the conversion (in precentage terms), between 2.8 and $41.7 \%$, depending on the other experimental conditions adopted (molar ratio, ultrasound amplitude and catalyst concentration). The response surface referring to the vibration pulse is shown in Figure 3(c,d), where it can be observed that there is an increase in the reaction conversion with the increase of the vibration pulse up to a value of $67.30 \%$. An additional increase in the pulse does not provide a significant increase in conversion. Mostafaei et al. (2015) performed a study in the production of biodiesel by the transesterification of used cooking oil in the presence of ultrasonic waves, varying the ultrasonic vibration pulse from 20 to $100 \%$ and found optimal conditions with a pulse of $62 \%$.

\section{Process Optimization}

Optimal reaction conditions were calculated through the experimental planning model presented in Table 1 and with the help of the software Statistic 8.0. The molar ratio was optimized at 1:14.87, catalyst concentration at $1.17 \%$, ultrasonic probe amplitude at $67.64 \%$ and vibration pulse at $67.30 \%$. The amplitude of the probe and the vibration pulse were rounded up to 68 and $70 \%$ respectively, because of operational limitations. Under these conditions, the model represented by equation (4) predicts that the reaction conversion will be $100 \%$. Three experiments were performed under optimal conditions and the results are shown in Table 4. With a conversion average of $98.12 \%$, this result fit well the predictions of the model that has $95 \%$ of reliability.
The conversion obtained in the interesterification reaction under optimal conditions of the process (over 98\%) is highly satisfactory in comparison to the literature. Maddikeri et al. (2013) achieved an ester yield of $90 \%$ using cooking oil with a molar ratio of $1: 12$, temperature of $40{ }^{\circ} \mathrm{C}$, catalyst concentration of $1 \%$ and ultrasonic probe amplitude of $60 \%$, these conditions being close to those optimized in the process. Casas et al. (2013) presented a 77\% yield of esters in the interesterification reaction of sunflower oil with a conventional approach, using $0.1 \%$ of catalyst, temperature of $50{ }^{\circ} \mathrm{C}$ and a molar ratio of $1: 48$. Since ultrasonic waves propagate in the form of a longitudinal wave with serial compressions and expansions, this oscillatory movement originates an intense "micro mixture", capable of producing a stronger emulsion than the one produced by mechanical agitation, increasing the conversion of triglycerides significantly (Choudhury et al., 2014a, 2014b; Mostafaei et al., 2015).

In order to complement the analysis, the yield of esters under optimized conditions was also evaluated, the yield being defined as the ratio of the mass of the produced esters to the mass of oil (TG) in the initial sample (Tan et al., 2011; Doná et al., 2013). The ester yield varied from $52.75 \%\left(50{ }^{\circ} \mathrm{C}, 1 \mathrm{~min}\right)$ to $98.51 \%$ $\left(50^{\circ} \mathrm{C}\right.$ and $\left.30 \mathrm{~min}\right)$, where increasing the temperature and reaction time resulted in an increase in ester yield.

\section{Kinetic Parameters Study}

To conduct the kinetic study, the experiments were performed under optimal conditions by the process model. Figure 4 shows the conversion of the triglycerides in the reaction at different temperatures.

The interesterification reaction is a fast reaction, with conversions of $50 \%$ in just 1 minute. As expected, the temperature influenced the final reaction conversion, because the activation energy needs to be overcome so that the reaction can occur, and the increase in temperature increases the molecular agitation, causing higher conversions at higher temperatures. The data presented in Figure 4 were analyzed using the second order kinetic model, equation (2), to determine the reaction rate constants at different

Table 4. Experiments under optimal conditions of the model. [Reaction conditions: molar ratio of 1:14.87; catalyst concentration of $1.17 \%$; ultrasonic probe amplitude of $68 \%$; vibration pulse of $70 \%$ and; temperature of $50^{\circ} \mathrm{C}$ ]

\begin{tabular}{ccccccc}
\hline Experiment & A & B & C & D & Conversion (\%) \\
\hline 1 & 14.87 & 1.17 & 68.00 & 70.00 & 97.29 \\
2 & 14.87 & 1.17 & 68.00 & 70.00 & 100.00 \\
3 & 14.87 & 1.17 & 68.00 & 70.00 & 97.07 \\
\hline
\end{tabular}




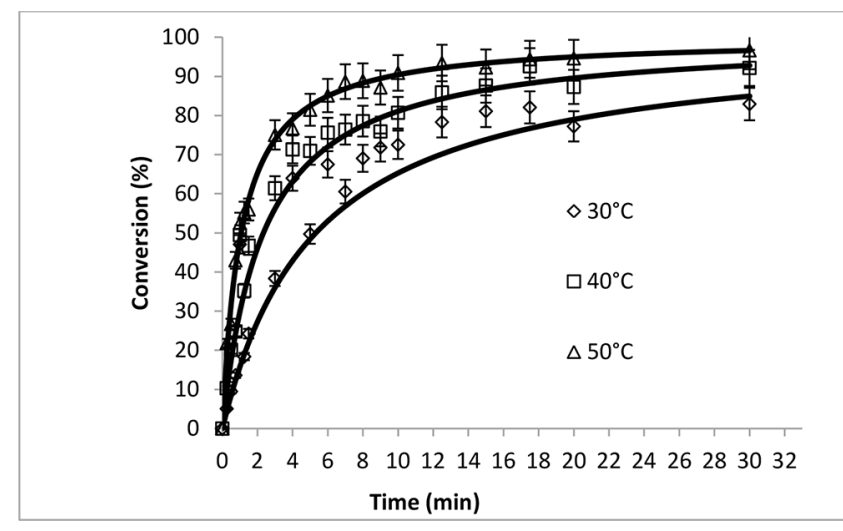

Figure 4. Kinetic curve of the reaction at various temperatures. [Reaction conditions: molar ratio of $1: 14.87$; catalyst concentration of $1.17 \%$; ultrasonic probe amplitude of $68 \%$ and; vibration pulse of $70 \%$ ].

temperatures. The assumptions of irreversibility of the reaction is favored with the excess of methyl acetate, inducing a lower concentration of triglycerides when balance is achieved in the reaction medium, similar to an irreversible reaction (Maddikeri et al., 2013). Data referring to the behavior of a second order reaction at different reaction temperatures $\left(30,40\right.$ and $\left.50^{\circ} \mathrm{C}\right)$ are presented in Figure 5. According to equation (3), the angular coefficient of each line in Figure 5 represents the reaction rate constant at each temperature. The constants and their respective correlation coefficients are shown in Table 5. The correlation coefficient values indicate that the experiment at $50{ }^{\circ} \mathrm{C}$ resulted in a better model fitting. However, experiments performed at different temperatures achieved satisfactory correlation coefficients, according to the second order reaction assumption for the interesterification $\left(\mathrm{R}^{2}=0.997\right)$.

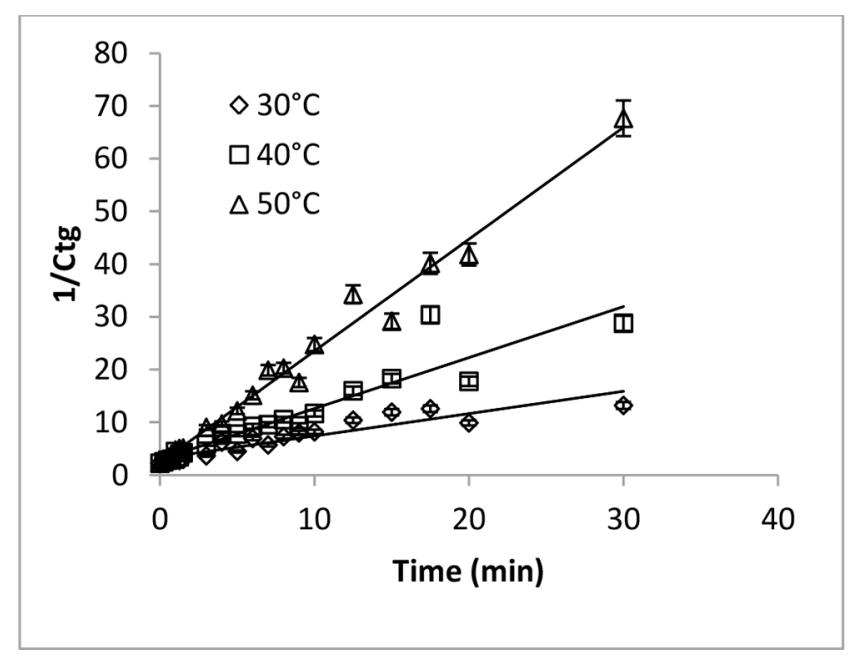

Figure 5. Reaction rate constant under various temperatures.
An increase in the reaction rate constant was observed with the increase in temperature from 0.424 $\mathrm{L} \mathrm{mol}^{-1} \mathrm{~min}^{-1}\left(30{ }^{\circ} \mathrm{C}\right)$ to $2.122 \mathrm{~L} \mathrm{~mol}^{-1} \mathrm{~min}^{-1}\left(50{ }^{\circ} \mathrm{C}\right)$. Similar tendencies treating the interesterification reaction as a second order reaction have been reported by Maddikeri et al. (2013), where cooking oil was utilized in the presence of ultrasonic waves, in different temperatures. Casas et al. (2011a) worked in the interesterification of sunflower oil in conventional conditions and also pointed out that the reaction rate increases with the increase of the temperature. This happens because the increase in temperature increases the molecular agitation, increasing the number of effective collisions that favor a faster processing of the reaction. The reaction rate is also increased due to a higher interfacial area between the triglycerides and the methyl acetate resulting from the cavitation effects, mainly by the high levels of turbulence generated in the reaction mixture. These effects are also responsible for the creation of micro emulsions between the two reaction phases. Consequently, the interfacial area between the reactants increases considerably, resulting in higher reaction rates and requiring milder temperatures (Deshmane et al., 2009).

Using the reaction rate constants (presented at Table 5), and their respective temperatures, it was possible to plot the graph of the neperian logarithm of the reaction rate as a function of the inverse of temperature, as presented at Figure 6.

Table 5. Reaction rate constant and activation energy.

\begin{tabular}{cccc}
\hline $\mathrm{T}\left({ }^{\circ} \mathrm{C}\right)$ & $\mathrm{k}^{\prime}\left(\mathrm{L} \mathrm{mol}^{-1} \mathrm{~min}^{-1}\right)$ & $\mathrm{R}^{2}$ & $\mathrm{E}_{\mathrm{a}}\left(\mathrm{kJ} \mathrm{mol}^{-1}\right)$ \\
\hline 30 & 0.424 & 0.858 & \\
40 & 0.966 & 0.881 & $65.541 \mathrm{R}^{2}=0.997$ \\
50 & 2.122 & 0.983 & \\
\hline
\end{tabular}

The angular coefficient of this line (Figure 6) represents the ratio between the activation energy and the universal gas constant $\left(-\mathrm{E}_{\mathrm{a}} / \mathrm{R}\right)$, while the linear coefficient represents the naperian logarithm of the pre-exponential frequency factor. Therefore, the activation energy value obtained was $65.541 \mathrm{~kJ} \mathrm{~mol}^{-1}$ and the frequency factor was verified to be $8.37 \times 10^{10}$ $\mathrm{L} \mathrm{mol}^{-1} \mathrm{~min}^{-1}$. The activation energy value found in the interesterification reaction with the ultrasound is close to the value reported by Maddikeri et al. (2013) of $58.170 \mathrm{~kJ} \mathrm{~mol}^{-1}$, where the authors performed a kinetic study of the interesterification of used cooking oil with 
ultrasound. Campanelli et al. (2010) presented a study of the synthesis of supercritical biodiesel through the interesterification of diverse edible and non-edible oils and identified that the activation energy is dependent of the nature of the vegetable oils. The Arrhenius equation resulting for the interesterification reaction of the cotton oil in the presence of ultrasonic waves is given by equation (5).

$$
k^{\prime}=8.37 \cdot 10^{10} \cdot \exp \left[\frac{-65541}{R T}\right]
$$

Although the model presented here was the model of second-order irreversible reaction approximation, the good fit found $\left(\mathrm{R}^{2}=0.997\right)$ indicated that the interesterification reaction follows a second-order reaction scheme; this is reasonable because, according to Casas et al. (2011a), interesterification is similar to a pair of coupled transesterification reactions.

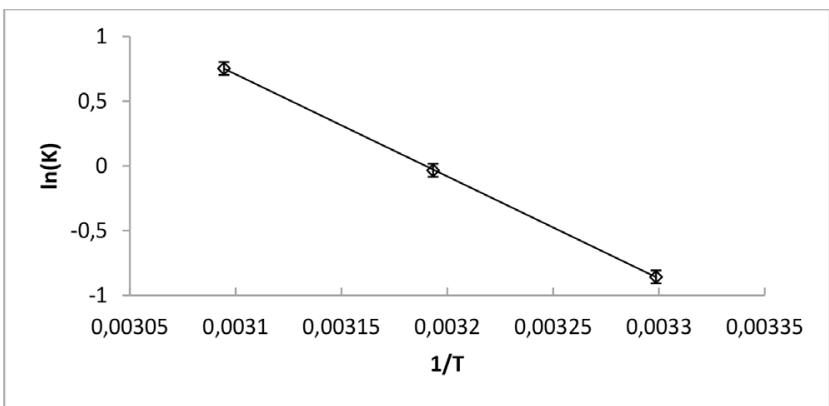

Figure 6. Kinetic study of the activation energy.

\section{Comparison of ultrasound with the conventional method}

Conventional experiments with mechanical agitation were performed to compare with the ultrasound production of biodiesel. Figure 7 shows the data of the experiments performed (conversion) with mechanical agitation using conditions optimized by the model presented in equation (4) and the data of the ultrasound experiments at $50{ }^{\circ} \mathrm{C}$, presented in Figure 4. As a complement, the yields of esters under the optimized conditions were also evaluated, where the highest ester yield in the conventional technique was $84.61 \%$, while in the ultrasonic technique the yield was $98.51 \%$. Both results occurred at 30 minutes reaction and $50{ }^{\circ} \mathrm{C}$.

It can be noted that the interesterification reaction using ultrasound ( $98 \%$ on average, Table 4 ), is more elevated than the production of biodiesel by the conventional technique $(84 \%)$, i.e., the use of ultrasound resulted in an increase of $14 \%$ of conversion. Literature reports also show similar

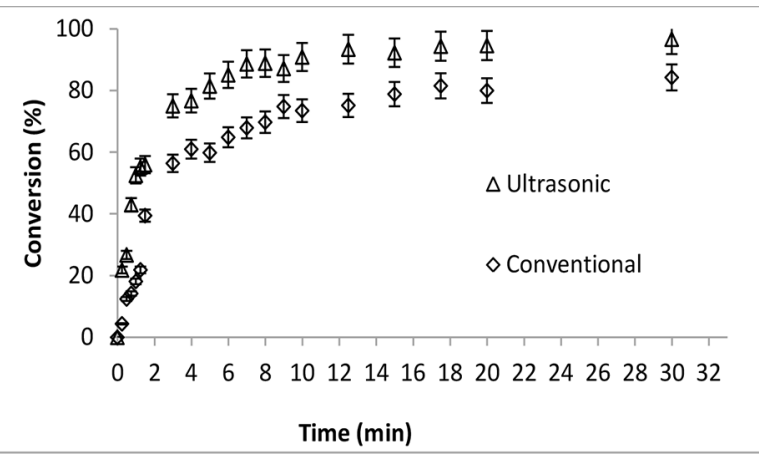

Figure 7. Comparative study of the production of biodiesel via ultrasound and mechanical agitation. [Reaction conditions: molar ratio of 1:14.87; catalyst concentration of $1.17 \%$; ultrasonic probe amplitude of $68 \%$ and; vibration pulse of $70 \%$ ].

tendencies. Maddikeri et al. (2013) compared the interesterification of used cooking oil with ultrasound with a conventional approach. Using a molar ratio of $1: 12$, catalyst concentration of $1 \%$ in weight and temperature of $40{ }^{\circ} \mathrm{C}$, they verified a yield of $90 \%$ with ultrasound and $70 \%$ with the conventional method. Subhedar et al. (2015) studied the synthesis of biodiesel through enzymatic transesterification of sunflower oil, both with the conventional method and assisted by ultrasound. The authors performed experiments with an enzymatic load of $5 \%$ of weight/ volume and temperature of $40{ }^{\circ} \mathrm{C}$. The results showed that the yield of the ultrasound reaction achieved $95 \%$ in 4 hours, while the conventional method achieved a yield of $60 \%$ after 24 hours. The use of ultrasonic irradiation provides higher conversion levels due to the physical effects provided by the cavitation phenomenon. This phenomenon causes higher conversions due to the intense local turbulence, which creates a microcirculation in liquids and the formation of micro emulsion, resulting in an increase in the interfacial area available between the two phases that participate in the reaction, resulting in the increase of the reaction rate.

In general, the literature (Mostafaei et al., 2015; Hingu et al., 2010) states that the ultrasonic technique requires lower costs compared to traditional (mechanical agitation), and this is due to several factors, including because the ultrasonic decreases energy use, since it provides a large amount of energy for the reaction mixture, and as a consequence, the temperature increases easily. As a result, there is no requirement for external heating and intense mechanical agitation in the production process (Vyas et al., 2010; Koh and Ghazi, 2011; Veljković et al., 2012; Badday et al., 2012).

In this work, the energy requirements of the experimental equipment using ultrasonic were reduced 
to $2 / 3$ in relation to the experiments using mechanical agitation $\left(3.6 \mathrm{~kJ} \times 10^{3}\right)$. Similar behavior was reported by Lourinho and Brito (2015), who state that ultrasonic works better and with lower energy consumption compared to conventional agitation processes (Vyas et al., 2010; Banković-Ilić et al., 2012).

In relation to the reaction rate constant, it was verified in this paper that, at the temperature of $50^{\circ} \mathrm{C}$, the rate constant for the reaction using mechanical agitation was $0.407 \mathrm{~L} / \mathrm{mol} \cdot \mathrm{min}$. This value is close to the value of the constant with ultrasound at the temperature of $30{ }^{\circ} \mathrm{C}$ (Table 5), concluding that with ultrasound there was an increase of the reaction rate and reaction in a shorter time (Figure 7). This means the use of milder temperatures and shorter reaction times, and consequently lower energy requirements.

Although not discussed in this paper, another advantage offered by the use of the ultrasound approach is related to the lower excess of methyl acetate required to reach a similar or higher level of conversions (Maddikeri et al., 2013). A lower requirement of excess methyl acetate will certainly decrease the overall energy of the process, since methyl acetate separation (usually by distillation) is a very energy intensive operation.

Ultrasonic technology has acquired attention of researchers for its use on a large scale. Asgharzadehahmadi et al. (2016) conducted a detailed review of the literature on the applicability of sonochemical reactors in chemical processes and concluded that they are not yet used industrially due to unavailability of information on their characteristics and performance. Scaling up is hampered by the fact that information is required from a variety offields, such as chemical engineering (gas-liquid hydrodynamics and other reactor operations), materials science (construction of transducers operating efficiently under high frequency and high energy dissipation), acoustics (for a better understanding of the sound field in the reactor). There seem to be considerable technical and economic limitations and virtually no industrial scale processing is being carried out. Undoubtedly, the combined efforts of chemists, physicists, chemical engineers, and equipment manufacturers will be necessary to enable the use of ultrasonic energy as a viable option for the intensification of the process (Gogate et al., 2003).

\section{CONCLUSION}

The present work intensified the study of biodiesel production by interesterification using ultrasonic waves, showing it to be a promising alternative to transesterification. Through an experimental planning and a response surface analysis, it was possible to study the variables that influenced the process and develop a model capable of accomplishing optimization. The model generated optimized the molar ratio to $1: 14.87$, catalyst concentration to $1.17 \%$, ultrasonic probe amplitude to $67.64 \%$ and vibration pulse to $67.30 \%$. Under these conditions, the model predicts complete conversion of the triglycerides. The kinetic study of the reaction performed at temperatures of 30,40 and $50{ }^{\circ} \mathrm{C}$ indicated that it is a second order reaction and that the reaction rate constant increases with the temperature increase. The highest reaction rate constant was verified at $50{ }^{\circ} \mathrm{C}\left(2.122 \mathrm{~L} \mathrm{~mol}^{-1} \mathrm{~min}^{-1}\right)$ and the activation energy was quantified at 65.541 $\mathrm{kJ} / \mathrm{mol}$. The experiments performed under optimized conditions with a conventional methodology (mechanical agitation) were compared to experiments using ultrasound. Therefore, the results obtained from the use of ultrasonic waves are highly significant, since an increase of $14 \%$ in the conversion of triglycerides with the use of ultrasonic waves was achieved in relation to the conventional methodology.

\section{ACKNOWLEDGEMENT}

The authors are grateful to the Chemical Engineering Postgraduate Program from the Federal University of Rio Grande do Norte and CAPES, for the financial support.

\section{REFERENCES}

Asgharzadehahmadi, S.; Raman, A. A. A.; Parthasarathy, R.; Sajjadi, B. Sonochemical reactors: Review on features, advantages and limitations. Renewable and Sustainable Energy Reviews, 63, 302-314 (2016).

Badday, A. S.; Abdullah, A. Z.; Lee, K. T., Khayoon, M. S. Intensification of biodiesel production via ultrasonic-assisted process: A critical review on fundamentals and recent development. Renewable and Sustainable Energy Reviews, 16, 4574-4587 (2012).

Bang, J. H.; Suslick, K. S. Applications of ultrasound to the synthesis of nanostructured materials. Advanced Materials, 22, 1039-1059 (2010).

Banković-Llić, I. B.; Stamenković, O. S.; Veljković, V. B. Biodiesel production from non-edible plant oils. Renewable and Sustainable Energy Reviews, 16, 3621-3647 (2012).

Behçet, R.; Oktay, H.; Çakmak, A.;Aydin, H. Comparison of exhaust emissions of biodiesel- 
diesel fuel blends produced from animal fats. Renewable and Sustainable Energy Reviews, 46, 157-165 (2015).

Bonet, J.; Costa, J.; Sire, R.; Reneaume, J. M.; Pleşu, A. E.; Plesu, V.;Bozga, G. Revalorization of glycerol: Comestible oil from biodiesel synthesis. Food and Bioproducts Processing, 87, 171-178 (2009).

Campanelli, P.; Banchero, M.; Manna, L. Synthesis of biodiesel from edible, non-edible and waste cooking oils via supercritical methyl acetate transesterification. Fuel, 89, 3675-3682 (2010).

Casas, A.; Ruiz, J. R.; Ramos, M. J.; Pérez, Á. Effects of triacetin on biodiesel quality. Energy and Fuels, 24, 4481-4489 (2010).

Casas, A.; Ramos, M. J.; Pérez, Á. Kinetics of chemical interesterification of sunflower oil with methyl acetate for biodiesel and triacetin production. Chemical Engineering Journal, 171, 1324-1332 (2011a).

Casas, A.; Ramos, M. J.; Pérez, Á. New trends in biodiesel production: Chemical interesterification of sunflower oil with methyl acetate. Biomass and Bioenergy, 35, 1702-1709 (2011b).

Casas, A.; Ramos, M. J.; Pérez, Á. Methanol-enhanced chemical interesterification of sunflower oil with methyl acetate. Fuel, 106, 869-872 (2013).

Cerveró, J. M.; Coca, J.; Luque, S. Production of biodiesel from vegetable oils. Grasas y Aceites, 59, 76-83 (2008).

Choudhury, H. A.; Goswami, P. P.; Malani, R. S.; Maholkar, V. S. Ultrasonic biodiesel synthesis from crude Jatropha curcas oil with heterogeneous base catalyst: Mechanistic insight and statistical optimization. Ultrasonics Sonochemistry, 21, 1050-1064 (2014a).

Choudhury, H. A.; Chakma, S.; Moholkar, V. S. Mechanistic insight into sonochemical biodiesel synthesis using heterogeneous base catalyst. Ultrasonics Sonochemistry, 21, 169-181 (2014b).

Deshmane, V. G.; Gogate, P. R.; Pandit, A. B. Ultrasound assisted synthesis of isopropyl esters from palm fatty acid distillate. Ultrasonics Sonochemistry, 16, 345-350 (2009).

Doná, G.; Cardozo-Filho, L.; Silva, C.; Castilhos, F. Biodiesel production using supercritical methyl acetate in a tubular packed bed reactor. Fuel Processing Technology, 106, 605-610 (2013).

Du, W.; Xu, W.; Liu, D.; Zeng, J. Comparative study on lipase-catalyzed transformation of soybean oil for biodiesel production with different acyl acceptors.
Journal of Molecular Catalysis B: Enzymatic, 30, 125-129 (2004).

El-Gendy, N. S.; Deriase, S. F.; Hamdy, A.; Abdallah, R. I. Statistical optimization of biodiesel production from sunflower waste cooking oil using basic heterogeneous biocatalyst prepared from eggshells. Egyptian Journal of Petroleum, 24, 37-48 (2015).

Galia, A.; Centineo, A.; Saracco, G.; Schiavo, B.; Scialdone, O. Interesterification of rapeseed oil catalyzed by tin octoate. Biomass and Bioenergy, 67, 193-200 (2014).

Gogate, P. R.; Mujumdar, S.; Pandit, A. B. Large-scale soonochemical reactors for process intensification: design and experimental validation. Journal of Chemical Technology and Biotechnology, 78, 685693 (2003).

Gogate, P. R.; Kabadi, A. M. A review of applications of cavitation in biochemical engineering/ biotechnology. Biochemical Engineering Journal, 44, 60-72 (2009).

Gole, V. L.; Gogate, P. R. A review on intensification of synthesis of biodiesel from sustainable feed stock using sonochemical reactors. Chemical Engineering and Processing: Process Intensification, 53, 1-9 (2012).

Gole, V. L.; Gogate, P. R. Intensification of synthesis of biodiesel from non-edible oil using sequential combination of microwave and ultrasound. Fuel Processing Technology, 106, 62-69 (2013).

Hingu, S. M.; Gogate, P. R.; Rathod, V. K. Synthesis of biodiesel from wast cooking oil using sonochemical reactors. Ultrasonics Sonochemistry, 17, 827-832 (2010).

Jesus, A. A.; Almeida, L. C.; Silva, E. A.; Filho, L. C.; Egues, S. M. S.; Franceschi, E.; Fortuny, M.; Santos, A. F.; Araújo, J.; Sousa, E. M. B. D.; Dariva, C. Extraction of palm oil using propane, ethanol and its mixtures as compressed solvent. Journal of Supercritical Fluids, 81, 245-253 (2013).

Kalva, A.; Sivasankar, T.; Moholkar, V. S. Physical mechanism of ultrasound-assisted synthesis of biodiesel. Industrial and Engineering Chemistry Research, 48, 534-544 (2009).

Koh, M. Y.; Ghazi, T. I. M. A review of biodiesel production from Jatropha curcas L. oil. Renewable and Sustainable Energy Reviews, 15, 2240-2251 (2011).

Maddikeri, G. L.; Pandit, A. B.; Gogate, P. R. Ultrasound assisted interesterification of waste cooking oil and methyl acetate for biodiesel and 
triacetin production. Fuel Processing Technology, 116, 241-249 (2013).

Meher, L. C.; Sagar, D. V.; Naik, S. N. Technical aspects of biodiesel production by transesterification A review. Renewable and Sustainable Energy Reviews, 10, 248-268 (2006).

Mostafaei, M.; Ghobadian, B.; Barzegar, M.; Banakar, A. Optimization of ultrasonic assisted continuous production of biodiesel using response surface methodology. Ultrasonics Sonochemistry, 27, 5461 (2015).

Narváez, P. C.; Rincón, S. M.; Sánchez, F. J. Kinetics of palm oil methanolysis. JAOCS, Journal of the American Oil Chemists' Society, 84(10), 971-977 (2007).

Oasmaa, A.; Elliott, D. C.; Mu, S. Quality Control in Fast Pyrolysis Bio-Oil Production and Use. Environmental Progress, 28, 404-409 (2009).

Saka, S.; Isayama, Y. A new process for catalyst-free production of biodiesel using supercritical methyl acetate. Fuel, 88, 1307-1313 (2009).

Sánchez-Cantú, M.; Reyes-Cruz, F. M.; Rubio-Rosas, E.; Pérez-Díaz, L. M.; Ramírez, E.; Valente, J. S. Direct synthesis of calcium diglyceroxide from hydrated lime and glycerol and its evaluation in the transesterification reaction. Fuel, 138, 126-133 (2014).

Subhedar, P. B.; Botelho, C.; Ribeiro, A.; Castro, R.; Pereira, M. A.; Gogate, P. R.; Cavaco-Paulo, A. Ultrasound intensification suppresses the need of methanol excess during the biodiesel production with Lipozyme TL-IM. Ultrasonics Sonochemistry, 27, 530-535 (2015).

Subhedar, P. B.; Gogate, P. R. Ultrasound assisted intensification of biodiesel production using enzymatic interesterification. Ultrasonics Sonochemistry, 29, 67-75 (2016).
Suppalakpanya, K.; Ratanawilai, S. B.; Tongurai, C. Production of ethyl ester from esterified crude palm oil by microwave with dry washing by bleaching earth. Applied Energy, 87, 2356-2359 (2010).

Suslick, K. S. Editorial. Science, 28, 279 (1990).

Tan, K. T.; Lee, K. T.; Mohamed, A. R. A glycerolfree process to produce biodiesel by supercritical methyl acetate technology: An optimization study via Response Surface Methodology. Bioresource Technology, 101, 965-969 (2010).

Tan, K. T.; Lee, K. T.; Mohamed, A. R. Prospects of non-catalytic supercritical methyl acetate process in biodiesel production. Fuel Processing Technology, 92, 1905-1909 (2011).

Trentin, C. M.; Lima, A. P.; Alkimim, I. P.; Silva, C.; Castilhos, F.; Mazutti, M. A.; Oliveira, J. V. Continuous production of soybean biodiesel with compressed ethanol in a microtube reactor using carbon dioxide as co-solvent. Fuel Processing Technology, 92, 952-958 (2011).

Usai, E. M.; Gualdi, E.; Solinas, V.; Battistel, E. Simultaneous enzymatic synthesis of FAME and triacetyl glycerol from triglycerides and methyl acetate. Bioresource Technology, 101, 7707-7712 (2010).

Veljković, V. B.; Avramović, J. M.; Stamenković, O. S. Biodiesel production by ultrasound-assisted transesterification: State of the art and the perspectives. Renewable and Sustainable Energy Reviews, 16, 1193-1209 (2012).

Vyas, A. P.; Verma, J. L.; Subrahmanyam, N. A review on FAME production processes. Fuel, 89, 1-9 (2010).

Yin, J. Z.; Xiao, M.; Song, J. B. Biodiesel from soybean oil in supercritical methanol with cosolvent. Energy Conversion and Management, 49, 908-912 (2008). 
